\section{TYPING BLOOD CELLS, ONE AT A TIME}

\section{Stephen W. Carmichael ${ }^{1}$ Mayo Clinic}

We are all familiar with the $\mathbf{4}$ groups of human blood types; $O, A, B$, and $A B$. Each group is characterized by specific molecules on the surface of the red blood cells (RBCs). Recently, Michel Grandbois, Wolfgang Dettmann, Martin Benoit, and Hermann Gaub have modified the atomic force microscope (AFM) to use the different affinities of these molecules to produce an image. ${ }^{2}$

A key step was to specifically functionalize the scanning probe tip of the AFM. What this means is to covalently attach an active molecule to the tip. The active molecule they used was a lectin derived from the snail Helix pomatia (this is the same snail valued by the French as escargot). This lectin binds specifically to molecules found on the surface of RBCs in blood group A ( $\mathrm{N}$-acetylgalactosamine-terminated glycolipids), but these molecules are not found in blood group $O$. But if the lectin was bound directly to the AFM tip, nonspecific adsorption to the specimens would occur. Grandbois et al. avoided this by tethering the lectin to the AFM tip with an amylose polymer that allowed the discrimination of specific unbinding events.

The specimen was a monolayer of RBCs from the $A$ and $O$ blood group. The concept was to sample the specimen with the functionalized tip so that a specific binding/unbinding event produced a bright pixel, and the lack of an event produced a dark pixel. The binding/unbinding event produced a force curve that yielded additional information. The first part of the curve correspond to the contact of the tip with the cell surface. At that point specific recognition between the tip and the cell surface occur but no adhesion signal is recorded. As the tip was subsequently withdrawn, the cantilever that the tip was mounted on deflected, producing the adhesion signal observed in the force curve. After it was withdrawn a certain distance, the bond between the lectin and the molecule would rupture, and the cantilever would spring back to its equilibrium position.

However, Grandbois et al. were concerned that the unbind- ing event was actually what they were observing. The problem was the molecule on the A cells was a sugar-coated lipid, that was not firmly anchored in the surface membrane. Imagine that your hand was coated (functionalized) with a substance that stuck only to carrot tops; not turnips or beets, or anything else. As you tapped your hand over the ground in your garden, you could feel that sometimes it would stick to a carrot top. As you raised your hand, you could feel a force that would cease by the time your hand was a foot or so off the ground. Did the coating on your hand release the carrot top, or did you pull the carrot out of the ground? Likewise, the lipid molecule could have been pulled from the surface relatively easily. Grandbois et al. concluded that if this problem occurs in the experiment, it may well be avoided by the high off-rate of the lectin-sugar pair during the acquisition time of one picture, meaning that the dynamics of the experiment indicate this is a non-destructive detection of the specific molecule on A cells.

Of course this demonstration of affinity imaging with the AFM was not meant to type RBCs. In fact, Grandbois et al. used conventional fluorescence microscopy to show a labeled lectin binding to $A$ cells, and not $O$ cells, with much better resolution than by affinity imaging. However, they also pointed out that the binding of the labeled lectin to the A cells was a destructive process since the lectin remained on the RBCs, altering the surface. In contrast, the functionalized AFM tip moved on, leaving the surface in its original condition.

Imaging with the AFM based on affinity, as demonstrated by Grandbois et al., has the potential to become a valuable tool. Specific surface molecules may be imaged as they are expressed on cells under different conditions and at different stages of development.

1 The author gratefully acknowledges Dr. Michel Grandbois for reviewing this article.

2 Grandbois, M., W. Dettman, M. Benoit, and H.E. Gaub, Affinity imaging of red blood cells using an atomic force microscope, J. Histochem. Cytochem. 48:719-724, 2000.

\section{$\boldsymbol{r}$ \\ Typing Blood Cells, One At A Time} Stephen W. Carmichael, Mayo Clinic

NEW AND/OR INTERESTING AT M\&M 2000 $8-20$

SPM Tip Convolution. .21 Robert Rossi, California Institute of Technology

Removing Halftone Patterns From Scanned Images. .22 John Russ, North Carolina State University Chris Russ, Reindeer Games, Inc.

Microwave Immunohistochemistry on Mohs Cryostat. .24 Sections

Diane G. Miller, Miller Consultant Services

$\mathrm{LN}_{2}$ Handling-Fact and Fiction .26 Bob Compton, Microscopy Today
Imaging Large Tissue Samples at High resolution 31 Robert Meyer, Meyer Instruments Inc.

$\mathrm{pH}$ Microscopy Applications . 32 Nomura Satoshi, Horiba R\&D Center

Philadelphia College of Osteopathic Medicine Examines.......34 Embryonic Cells to Find the Origin of Muscles With Image Analysis Software Kisha D. DeSandies and Gabriella Madden

Removing Platinum/Carbon From Mica. Charles Garber, SPI Supplies

Dehydrating Delicate Specimens for Light Microscopy. 37 John A. Kiernan, The University of Western Ontario

Chris Jeffrees, The University of Edinburgh 


\section{Ileed The BOAn T0L For Vour Milcroanal'sis Appliceton?}
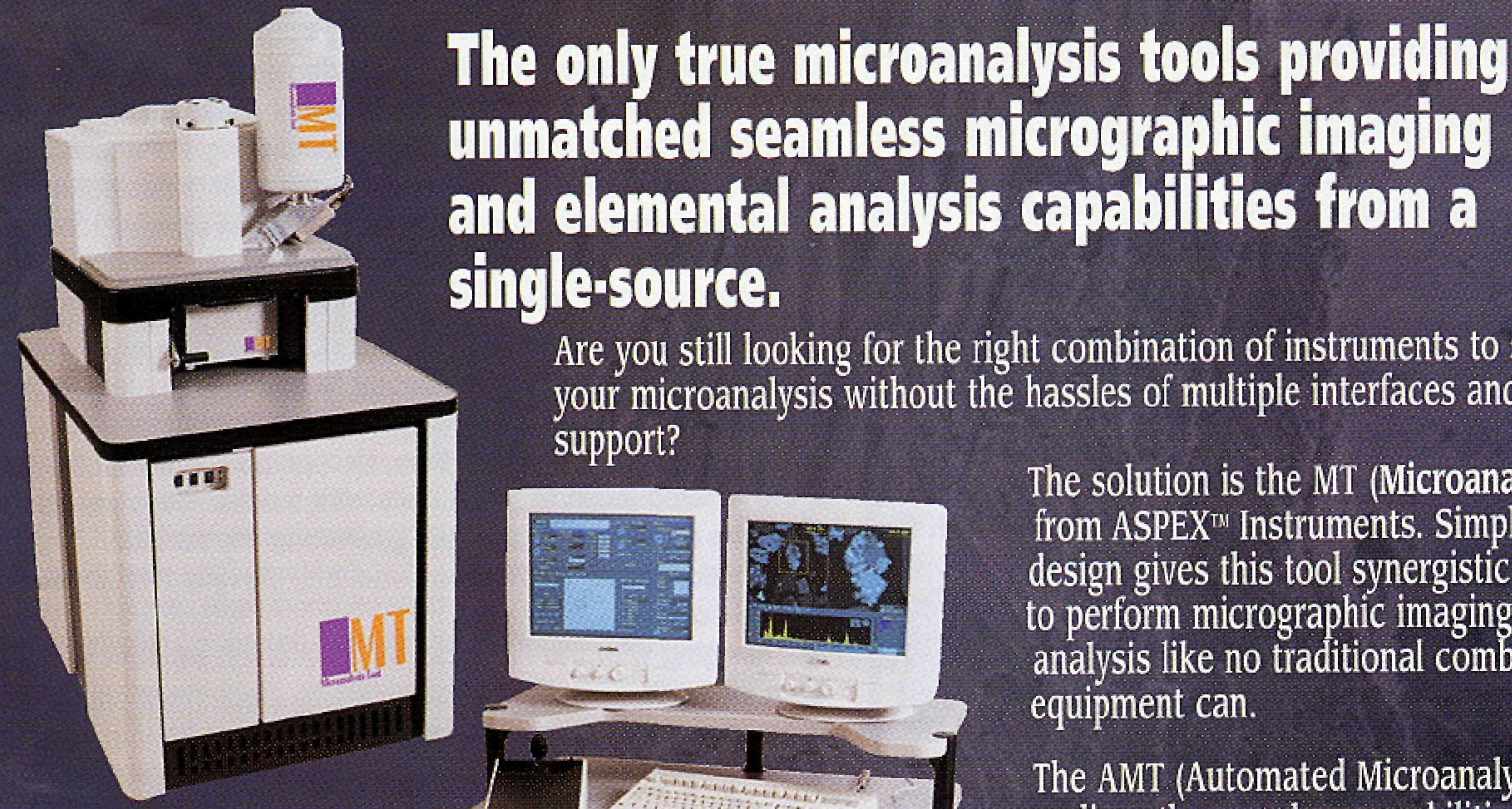

Are you still looking for the right combination of instruments to simplify your microanalysis without the hassles of multiple interfaces and proprietary

Both the AliI and Mill can be arstomited to meet spedific application requilements. support?

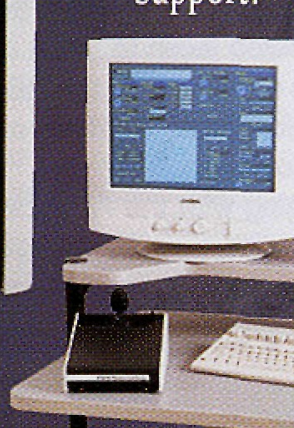

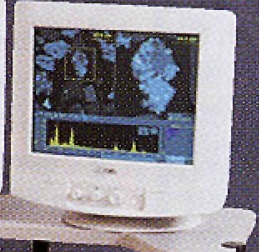

The solution is the MT (Microanalysis Tool) from ASPEX Instruments. Simplicity of design gives this tool synergistic power to perform micrographic imaging and analysis like no traditional combination of equipment can.

The AMT (Automated Microanalysis Tool) fully realizes the seamless capabilities of the MT, increasing efficiency and allowing automated processing for specific applications such as Gun Shot Residue, Metal Inclusion, Wear Debris, Contamination Analysis and many others.

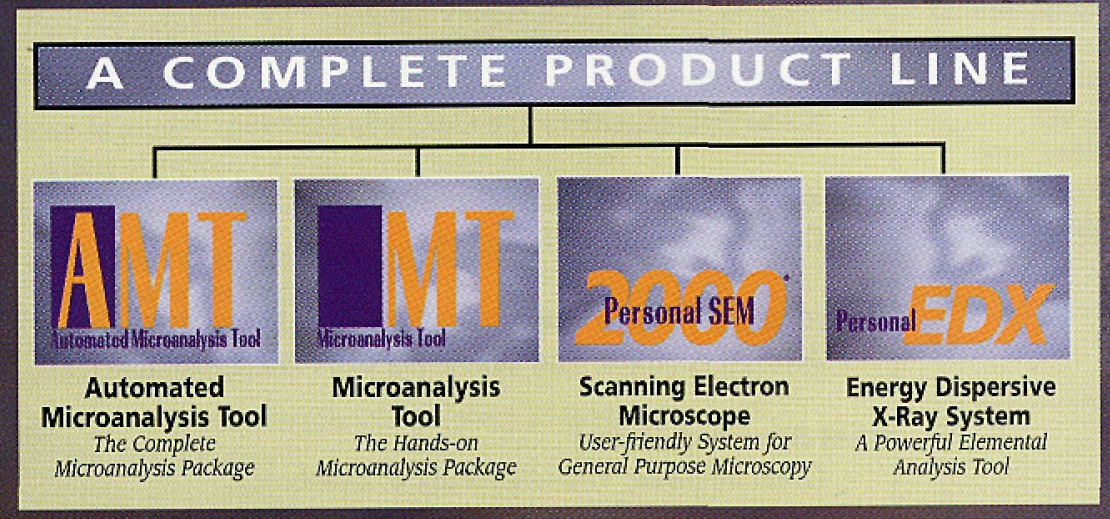

The MT and AMT are the industry's only true microanalysis tools, allowing users to focus on performing microanalysis rather than dealing with system functionality and integration issues.

ASPEX INSTRUMENTS

515 Pleasant Valley Road, Trafford, PA 15085 USA Phone 724.744 .0100

Fax 724.744.0506

Visit our Website: ASPEXLLC.com 


\section{PRESS RELEASE}

On August 14, 2000, RJ lee Instruments Limited completed it's metamorphosis to become ASPEX ${ }^{\mathrm{TM}}$, LLC. The Company will also utilize the trade name ASPEX ${ }^{T M}$ Instruments.

With the development of the only true Microanalysis Tools, the company has positioned itself as an industry leader in the desing, manufacture and service of highly productive, cost-effective automated tools for material characterization. To enhance their new identity and complete the metamorphosis, the company has become ASPEX ${ }^{\mathrm{TM}}$ Instruments.

As the catalyst for this change, these new Microanalysis Tools provide unmatched automated micrographic imaging and elemental analysis capabilities. This has allowed ASPEX to develop application specific tools for a variety of microanalysis applications such as Gun Shot Residue, Metal Inclusions, Wear Debris, and Natural Fibers, as well as many others.

For further information, contact:

Michael McCarthy

Tel.: (724)744-0100

Fax: (724)744-0506

\section{Analytical Laboratory Managers Association (ALMA) www.labmanagers.com}

ALMA is an association of analytical lab managers from industry, academic and government labs which focuses on management issues. Its principal activity is an annual meeting (normally in October) which focuses on a specific management issue. ALMA also supports education and training related to lab management and sponsors the publication of Managing The Modern Laboratory, a journal which publishes reviewed articles related to lab management.

$$
\begin{gathered}
\text { Keith Darlington, Atofina Chemicals } \\
\text { kdarlington@ato.com }
\end{gathered}
$$

\section{SURPLUS EQUIPMENT BOUGHT AND SOLD}

http://www.msa.microscopy.com/SurplusEquipment/

$$
\text { Surpluslistings.html }
$$

As sponsored by the Microscopy Society of America, Nestor Zaluzec announces the above web site to assist in the purchase and sale of used and surplus equipment.

The site is open to all individuals, organizations and vendors for the posting of electronic advertisement to dispose of surplus equipment-NOT new equipment.

He will review all postings to the site to make sure they are not junk/spam/bogus postings but will not be review for accuracy.

And while this service is at no charge, Dr. Zaluzec mentions that if one is able to dispose of surplus equipment at more than shipping costs, he/she might consider an appropriate contribution to MSA to help defray web operating costs.

However, if one is giving away equipment for at most nominal shipping costs, he/she is welcome to use the Microscopy Listserver-as it was created with that spirit in mind.

Lastly, this web site is not intended to replace the Vendor News Forum, which has been running for over a year at:

www.msa.microscopy.com/News/NewsListings.html
* Mike Coy has joined the JEOL USA Peabody SEM Applicatons Group. He previously managed both the Texas A\&M and Northwestern University SEM laboratories.

* The Nineteenth Annual Symposium on Advances in Microscopy will be held on 13-15 October 2000 at the Coastline Convention Center in Wilmington NC. As sponsored by the North Carolina Society for Microscopy and Microbeam Analysis (NCDMMA), the symposium has been planned with a theme of "Molecules, Cells \& Microchips." Continuing with the tradition of the symposium, the guest lecturers are composed of both nationally and internationally distinguished scientists. The meeting has several purposes, not the least of which is to draw attention of the scientific community to emerging developments in the practical and basic research aspects of exciting new fields, and to bring people together from diverse disciplines to discuss how innovative techniques will be relevant to the future direction of microscopy and microprobe analysis. In particular this year, special emphasis will be placed on how recent advances in electron, optical and probe microscopies have resulted in new knowledge that has benefited microscopy in general and are having a significant impact in the biological and physical sciences. The symposium also offers an opportunity for interested participants including students to submit abstracts of related studies for poster display.

Three special workshops/tutorials will be offered to participants in the Symposium: (a) Immuno/Microwave EM Techniques, (b) Atomic Force Microscopy and (c) Digital Imaging Methods. These are practical, introductory workshops/tutorials and no previous experience or knowledge is necessary.

For further information, contact Betty Gooch: Tel.: (919) 286-0411, eMail: b.gooch@cellbio.duke.edu

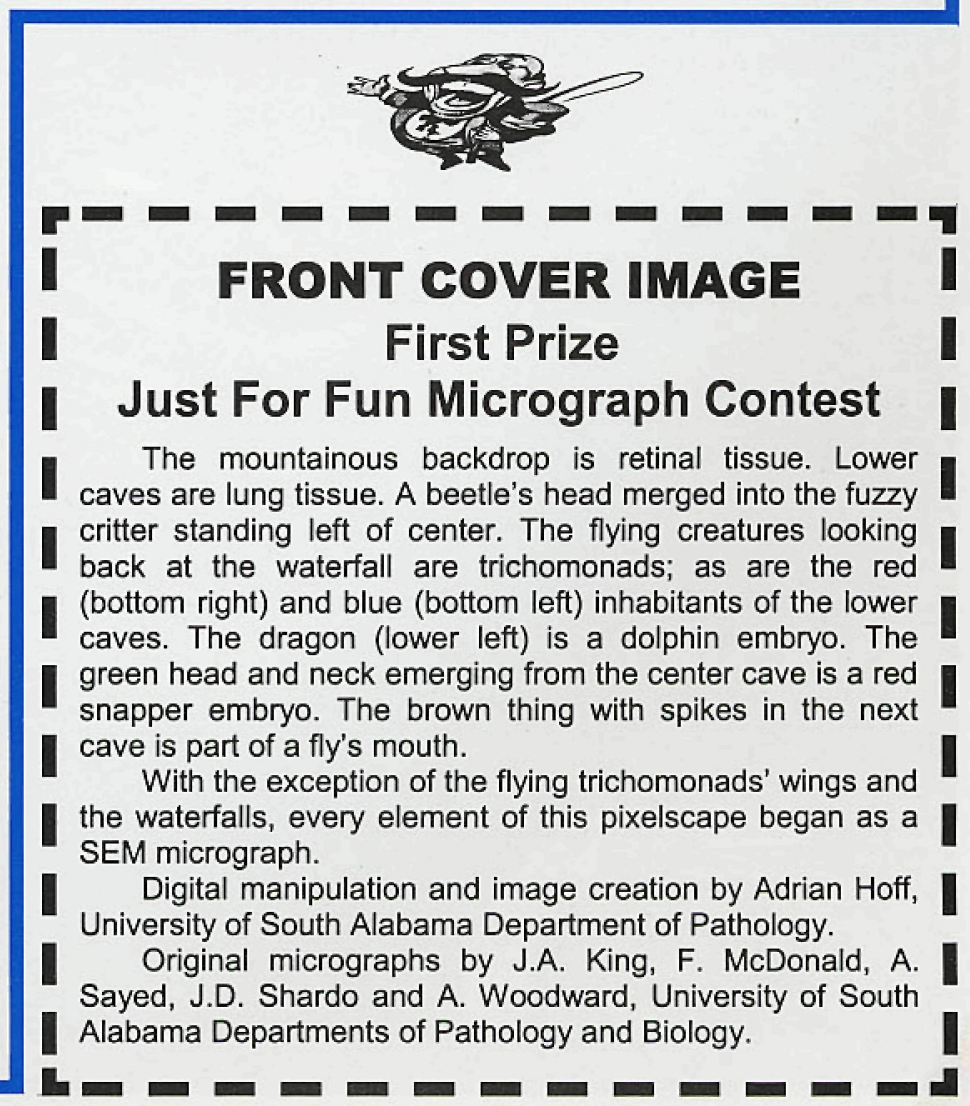




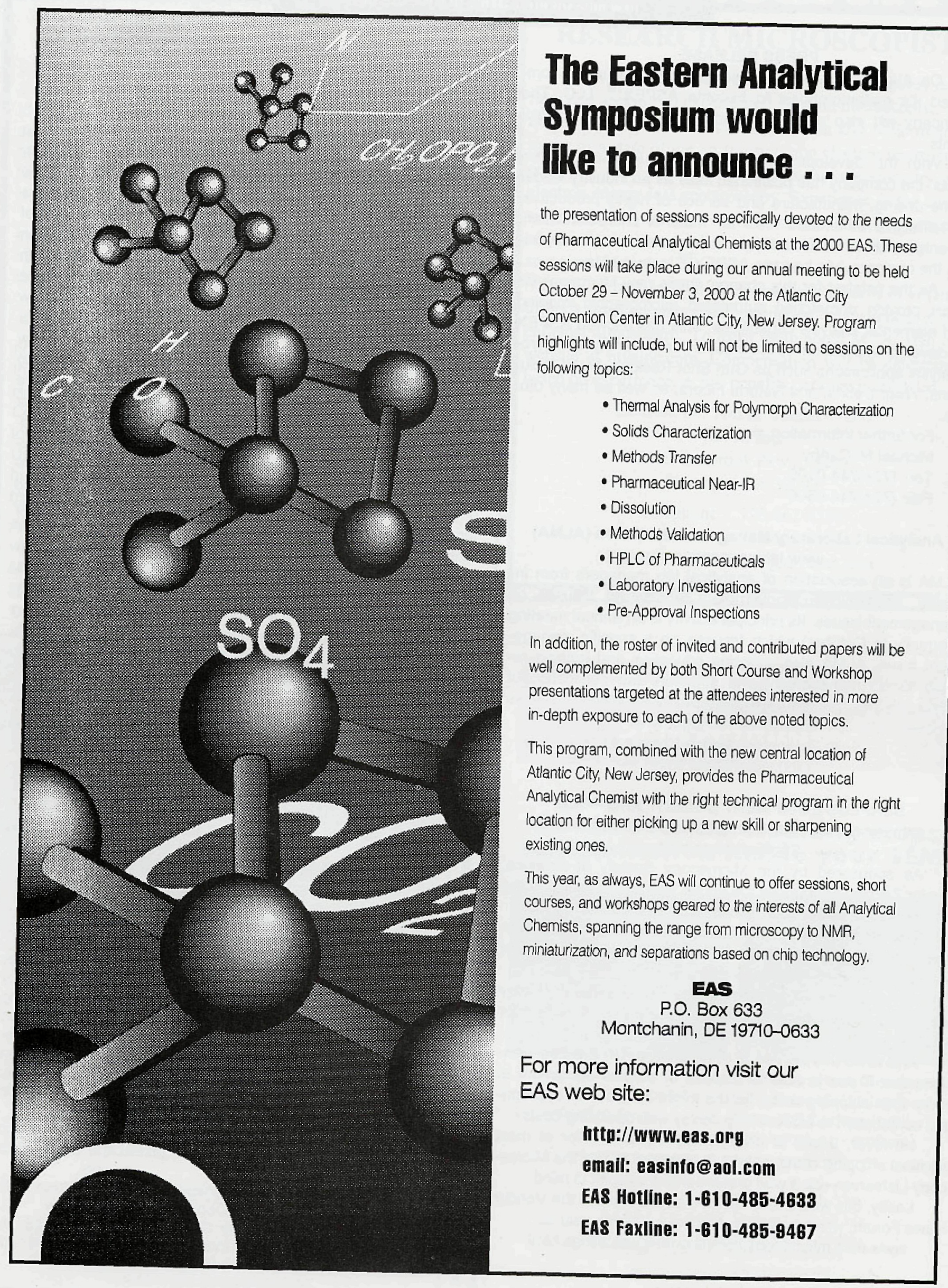




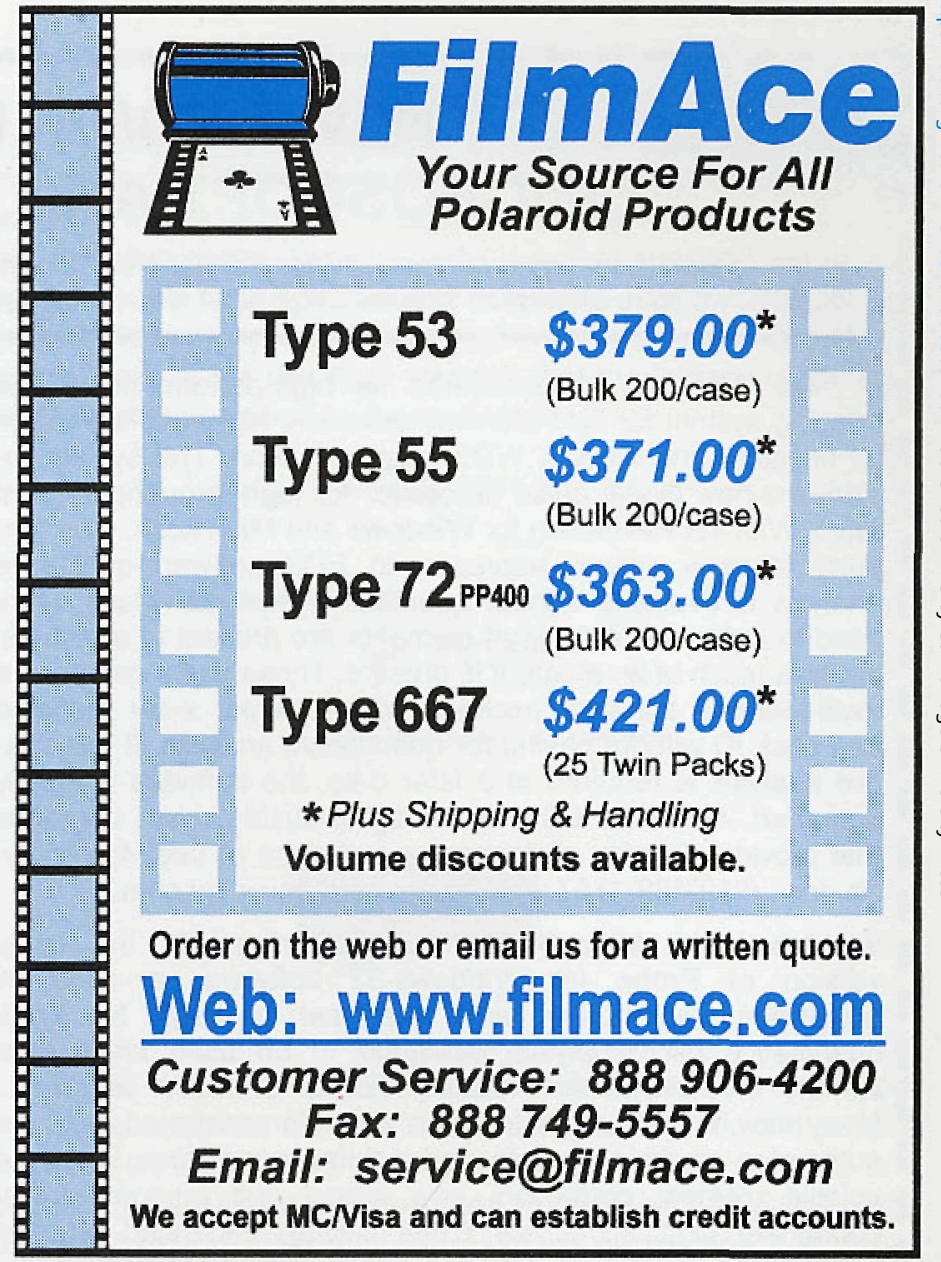

$\checkmark$ October 2 '00: TEM Short Course (American Vacuum Society) Boston, MA, www. vacuum.org

$\checkmark$ October 3/5 '00: SEM Applications Course Protrain/ANUEMU), Canberra, Australia: http://online.anu.edu.au/EMU/O0chapman.htm

$\checkmark$ October 8/13 '00: 3rd World Congress on Cellular and Molecular Biology. Jena, Germany, www.uni-jena,de/wccmb

$\checkmark$ October 11/19 '00: Optical Microscopy \& Imaging in the Biomedical Sciences. (Marine Biological Laboratory), Woods Hole, MA. Carol Hamel: (508)289-7401, admissions@mbl.edu

$\checkmark$ October 13/15 '00: Advances in Microscopy Symposium Wilmington, NC, http://152.3167.174/NCAnnSymp2000.html

$\checkmark$ October 16/20 '00: FLUORESCENCE 2000-Advanced Courses of Fluorescence Microscopy and Confocal Microscopy. Lake of Garda, Italy. Dr. Annalisa Imberti: +390270646234 , http://users.unimi.it/ $\sim f 2000 /$

$\checkmark$ October 16/20 '00: Trends in Nanotechnology 2000 Toledo, Spain, www.cientifica.com

$\checkmark$ October $17 / 19$ ' 00 : Fundamentals of Asbestos Analysis by Transmission Electron Microscopy (MVA, Inc.) Norcross GA: (770) $662-8509$

$\checkmark$ November 2/3 '00: EM At The Frontier (Naval Research Laboratory) Stennis Space Center, MS, matthew_hulbert@hotmail.com

$\checkmark$ November 6 '00: Chemical and Physical Nanotechnology Workshop (National Nanofabrication Users Network) Howard Univ, Washington, DC. www.cnf.cornell.edu/NNUNnowWorkshop.html

$\checkmark$ November 12/16 '00: International Symposium for Testing and Failure Analysis. http://www.edfas.org/istfa

$\checkmark$ November $13 / 17^{\prime} 00$, 8th Conference on Frontiers of Electron Microscopy in Materials Science (National Research Instituite for Metals) Matsue, Japan, www.nrim.go.jp/femms2000

$\checkmark$ November 13/17 '00: Particle Isolation, Manipulation and Mounting for Additional Analysis (McCrone Research Institute) Chicago, IL, Nancy Daerr, (312)842-7100, ndaerr@mcri.org

$\checkmark$ November 19/23 '00: First International Conference on Advanced Materials Processing Rotorua, New Zealand. Prof. Nigel Sammes: n.sammes@walkato.ac.nz

$\checkmark$ November 27/December '00: Scanning Electron Microscopy (McCrone Research Institute) Chicago, IL, Nancy Daerr, (312)842-7100, ndaer@@mcriorg

$\checkmark$ December $9 / 13^{~} 00$ : 40th Annual Meeting American Society for Cell Biology San Francisco, CA. www. ascb.org/ascb

\section{This is your final opportunity to win the digital camera}

Find Out How at

www.small-world.net 